\title{
IMPACT RESISTANT PERFORMANCE OF DUCTILE FIBER REINFORCED CEMENTITIOUS COMPOSITES (DFRCCs)
}

\author{
JEONGSOO NAM ${ }^{*}$, YASUJI SHINOHARA ${ }^{\dagger}$, TOSHIYUKI ATOU ${ }^{\dagger}$, \\ HONGSEOP KIM ${ }^{\dagger \dagger}$ AND GYUYONG KIM ${ }^{\dagger \dagger}$ \\ * Tokyo Institute of Technology, Yokohama, Japan \\ e-mail: nam.j.aa@m.titech.ac.jp \\ ${ }^{\dagger}$ Tokyo Institute of Technology, Yokohama, Japan \\ e-mail: shinohara.y.ab@m.titech.ac.jp \\ e-mail: atou.t.aa@m.titech.ac.jp \\ ${ }^{\dagger}$ Chungnam National University, Daejeon, Republic of Korea \\ e-mail: oliver-kahn12@nate.com \\ e-mail: gyuyongkim@cnu.ac.kr
}

Key words: DFRCCs, High Velocity Impact, Failure Mode, Penetration Path, Impact Resistance

\begin{abstract}
The aim of this study is to investigate the impact resistant performance of ductile fiber reinforced cementitious composites (DFRCCs) containing $1.5 \%$ volume fraction of polyvinyl alcohol and steel fibers subjected to high velocity impact of steel projectile (the diameter of $19.05 \mathrm{~mm}$ and the mass of $28.13 \mathrm{~g}$ ). To investigate the impact resistant performance of DFRCCs, gunpowder impact facility was used for impact tests, and the impact velocity was from about 450 to $750 \mathrm{~m} / \mathrm{s}$. The impact tests were also performed on non-fiber reinforced cementitious composite (Plain) specimens for comparison. The specimens were damaged in various failure modes, which are penetration, scabbing, and perforation. DFRCC specimens have superior capacity on the scabbing limit, and slightly bulged in the back side under the impact velocity of $700 \mathrm{~m} / \mathrm{s}$. The fibers play an important role in controlling the local damage of DFRCCs. In perforating, the debris of DFRCCs slightly scattered around a position of the back side in the cross section of the specimen.
\end{abstract}

\section{INTRODUCTION}

If an explosive accident occurs in the reinforced concrete (RC) structures, a careful attention should be paid to not only the total destruction of RC structures but also secondary damage by the scattered concrete and other fragment of the construction materials. In some cases, the fragments due to the explosion fly in all directions with high velocity more than several hundred $\mathrm{m} / \mathrm{s}$ [1]. Thus, the investigation of construction materials on the impact resistant performance to the high velocity collisions is required to establish a safety design for civil infrastructures, particularly important building and military facilities.

Over the past few decades, RC structures are most widely employed for protective structure fields because concrete materials have been high capability on the compression ability and durability compared with other construction materials. However, Concrete material is characterized as a brittle material compared with other composite materials under impact loads. This characteristic causes a critical cracking and local damage in the concrete structure [2-5]. Lee et al. [6] reported that the 
improvement of the fracture toughness by fiber sheet reinforcement in concrete strongly suppress the critical local damage, such as scabbing and perforation. This means that the ductile performance in flexure and tension is more important in order to increase the impact resistant performance of the concrete material.

To increase the flexural and tensile ductility of concrete structural members, ductile fiber reinforced cementitious composites (DFRCCs) have been applied to construction materials. DFRCC is possible to greatly control the cracking and spalling of the cement composite matrix by bridging actions of fibers. The advantages of DFRCC on the mechanical properties also increase the safety performance of the concrete structures subjected to dynamic impact loads [7-9].

Based on the above discussion, it is obvious that fibers contained in the cement mortar play an important role to control the cracking propagation, resulting in the improvement of the impact resistant performance. However the investigations on the impact resistance of DFRCC are still very few. In order to apply DFRCC to construction materials for the important structures, the influence of fiber characteristics on the impact resistance of DFRCC should be investigated by much higher velocity region. Moreover, a more detailed failure behavior which would be appeared from observation of a cross-section of damaged DFRCC, is still not clear.

Therefore, the objective of the this study is to investigate the failure behaviors of DFRCC specimens by a high velocity impact as well as the effects of short fiber type (polyvinyl alcohol fiber and steel fiber) on the failure modes. The constant fiber volume fraction of $1.5 \%$ was employed to DFRCC specimens for high velocity impact tests ranging from 450 to $750 \mathrm{~m} / \mathrm{s}$. The local damages of DFRCC specimens by the impact, such as penetration, scabbing, perforation, superficial damage, mass loss, and the internal damage patterns were examined and discussed. A critical local damage such as scabbing and perforation was also evaluated compared with non-fiber reinforced cement based composite (Plain) specimens. Consequentially, the obtained results are valuable to evaluate the resistance of DFRCCs to high velocity impact, particularly regarding the utilization of DFRCCs for important structures in civil and construction fields.

\section{EXPERIMENTAL PROGRAM}

\subsection{Materials and mixture proportions}

The properties of used materials in cementitious composite material mixtures are summarized in Table 1. Ordinary Portland cement was used as the binder for Plain and DFRCC mixtures $\left(875 \mathrm{~kg} / \mathrm{m}^{3}\right)$, and the class-F fly ash was also used as binder to improve the workability [10]. The class-7 silica sand was employed for each mixture. Superplasticizer (SP) was used to increase the fluidity for the each cementitious composite casting. All of the fibers have a length of $12 \mathrm{~mm}$ and a straight shape.

Table 2 shows the mixing proportions of cementitious composite, and the water/binder ratio (W/B) was set to 0.4 . Fly ash to binder ratio was around 0.2 in weight fraction. Three different mixture proportions are examined in this study. Each mixture has been labeled according to the fiber type. The fiber volume fraction in all of DFRCC specimens is $1.5 \%$.

Table 1: Material properties.

\begin{tabular}{ll}
\hline Materials & \multicolumn{1}{c}{ Properties } \\
\hline Cement & Ordinary Portland cement, \\
& Density: $3.15 \mathrm{~g} / \mathrm{cm}^{3}$, \\
& Fineness: $3,770 \mathrm{~cm}^{2} / \mathrm{g}$ \\
\hline Fly-ash & Class-F Type, \\
& Density: $2.20 \mathrm{~g} / \mathrm{cm}^{3}$, \\
& Fineness: $3,228 \mathrm{~cm}^{2} / \mathrm{g}$ \\
\hline Silica sand & Density: $2.56 \mathrm{~g} / \mathrm{cm}^{3}$, \\
& Absorption ratio: $0.49 \%$, \\
& Class-7 \\
\hline PVA fiber & Specific density: $1.3 \mathrm{~g} / \mathrm{cm}^{3}$, \\
& Diameter: $40 \mu \mathrm{m}, \mathrm{Length:} 12 \mathrm{~mm}$, \\
& Tensile strength: $1200 \mathrm{MPa}$, \\
& Elastic modulus: $32 \mathrm{GPa}$ \\
\hline steel fiber & Specific density: $7.8 \mathrm{~g} / \mathrm{cm}^{3}$, \\
& Diameter: $160 \mu \mathrm{m}, \mathrm{Length}: 12 \mathrm{~mm}$, \\
& Tensile strength: $2700 \mathrm{MPa}$, \\
& Elastic modulus: $200 \mathrm{GPa}$ \\
\hline
\end{tabular}


Table 2: Mixture proportions.

\begin{tabular}{llllll}
\hline ID & $\begin{array}{r}\mathrm{W} \\
/ \mathrm{B}\end{array}$ & $\begin{array}{c}\text { Fiber } \\
\left(\mathrm{V}_{f} \%\right)\end{array}$ & $\begin{array}{c}\text { Fly-ash } \\
\text { /binder } \\
(\text { wt.\%) }\end{array}$ & $\begin{array}{c}\text { Sand } \\
\text { /binder } \\
(\text { wt.\%) }\end{array}$ & $\begin{array}{c}\text { SP } \\
\text { /binder } \\
(\text { wt.\%) }\end{array}$ \\
\hline Plain & 0.4 & 0.0 & 20 & 40 & 0.0 \\
\hline PVAC & 0.4 & 1.5 & 20 & 40 & 0.5 \\
\hline SC & 0.4 & 1.5 & 20 & 40 & 0.2 \\
\hline
\end{tabular}

\subsection{Test methods}

In accordance with ASTM C39 and ASTM C469, the compressive strength and the elastic modulus were evaluated using a universal testing machine (UTM) and a compressometer with linear voltage differential transformers (LVDTs). In addition, the splitting tensile strength was measured according to ASTM C496 standard tests. All of static tests were performed using cylindrical cementitious composite specimens with a diameter of $100 \mathrm{~mm}$ and a height of $200 \mathrm{~mm}$. The specimens for static tests were cured in an environmental chamber at a temperature of $23 \pm 2{ }^{\circ} \mathrm{C}$ and a relative humidity of $60 \pm 5 \%$ during 28 days.

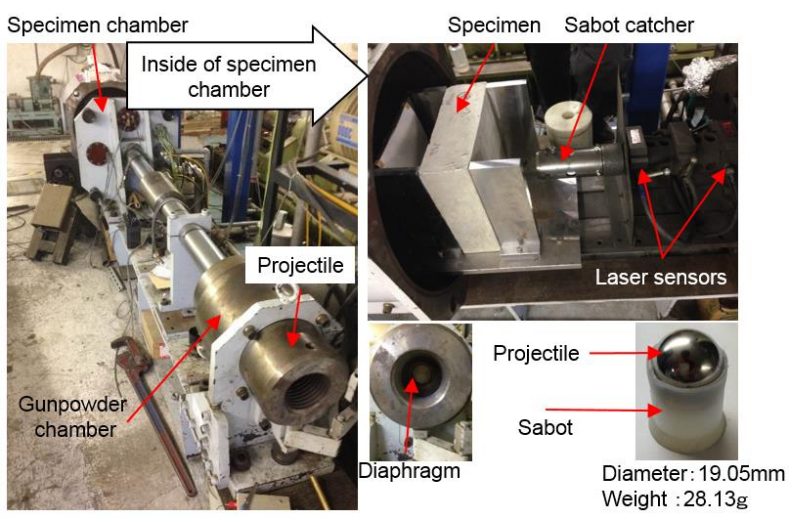

Figure 1: The gunpowder impact facility.

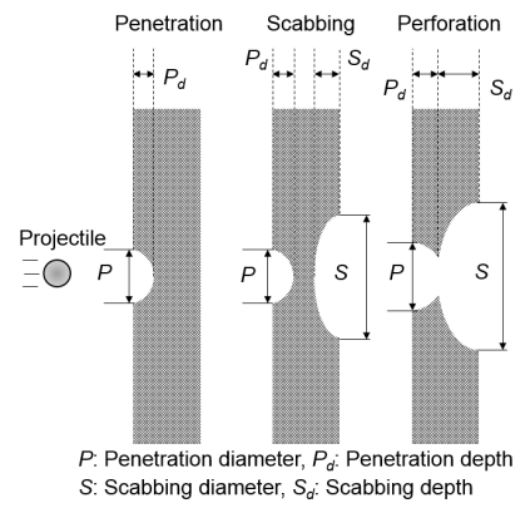

Figure 2: Measurement of local damage.
The dimension of the specimens for impact test was $300 \times 300 \times 100 \mathrm{~mm}$. The impact resistance of the test specimens was evaluated after 28 days curing in an environmental chamber at a temperature of $23 \pm 2{ }^{\circ} \mathrm{C}$ and a relative humidity of $60 \pm 5 \%$. The 304 spherical steel projectile (the diameter of $19.05 \mathrm{~mm}$ and the mass of $28.13 \mathrm{~g}$ ) was used in the impact test. The impact velocity range for DFRCC specimens was from about $450 \mathrm{~m} / \mathrm{s}$ to $750 \mathrm{~m} / \mathrm{s}$. The velocity of the projectile was measured by a laser beam cutting method. The projectile was glued on the nose of a sabot made of highdensity polyethylene to stabilize a trajectory. The sabot with projectile was accelerated by a single stage propellant gun [11]. The sabot was separated by a sabot-catcher just before colliding. The test specimen was fixed by two clamps at the left and right side to the steel frame in the specimen chamber. Figure 1 shows the gunpowder impact facility to evaluate impact resistant performance of DFRCCs.

Figure 2 shows the evaluation method of the failure mode and the local damage in the front and back side of a specimen. The diameter and depth of specimen after impact test were calculated from the maximum values for the penetration and scabbing measurements.

\section{RESULTS AND DISCUSSIONS}

\subsection{Mechanical properties}

Table 3 shows the results of the mechanical properties for each mixture at 28 days. The compressive strength of the test cylinders at 28 days are 55.2, 41.1 and 42.4 MPa for the Plain, PVAC and SC mixtures, respectively. Also, the elastic modulus of the Plain was higher than those of DFRCCs.

Table 3: Test results of the mechanical properties.

\begin{tabular}{lccc}
\hline \multicolumn{1}{|c}{ ID } & $\begin{array}{c}\text { Compressive } \\
\text { strength } \\
(\mathrm{MPa})\end{array}$ & $\begin{array}{c}\text { Elastic } \\
\text { modulus } \\
(\mathrm{GPa})\end{array}$ & $\begin{array}{c}\text { Splitting } \\
\text { tensile } \\
\text { strength } \\
(\mathrm{MPa})\end{array}$ \\
\hline Plain & $55.2(4.0)$ & $19.7(0.7)$ & $3.1(0.1)$ \\
\hline PVAC & $41.1(1.2)$ & $10.3(0.8)$ & $6.7(0.2)$ \\
\hline SC & $42.4(2.3)$ & $11.7(0.4)$ & $7.1(0.3)$ \\
\hline
\end{tabular}

Note: an average value of three time tests at 28 days, and values in parentheses are standard deviations. 
Meanwhile, the splitting tensile strength of the Plain was lower than those of DFRCCs to differ with the results of the compressive behavior. The splitting tensile strength of DFRCCs increased as a higher tensile strength of added fiber. It was concluded that PVAC and SC have a higher splitting tensile strength of about 2.1 and 2.2 times more than that of the Plain, respectively.

\subsection{Appearance of external damage}

The failure conditions of the Plain specimen and DFRCC specimens after the impact test under different velocity levels are shown in Figure 3. The damaged area of the perforated Plain specimen is widely distributed on the back side more than on the front side. It is well known when the perforation occurs due to the high velocity impact in the cementitious composites, the damage of the back side is severe as compared with that of the front side.

From the figure, it can be seen that DFRCC specimens have superior capacity on the scabbing limit, and slightly bulged in the back side under the impact velocity of $700 \mathrm{~m} / \mathrm{s}$. These results indicated that a remarkable impact resistance of DFRCC specimen increased. For PVAC and SC specimens, a bulge without scabbing was observed in the back side around the velocity of $670 \mathrm{~m} / \mathrm{s}$ and perforation occurred at the velocity above 700 $\mathrm{m} / \mathrm{s}$.

(a) Plain

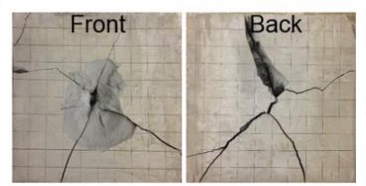

(b) PVAC

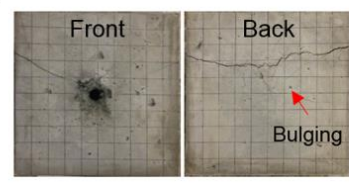

(c) SC

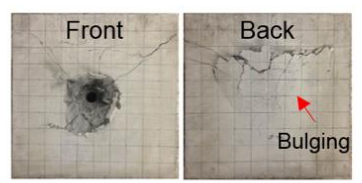

$678 \mathrm{~m} / \mathrm{s}$

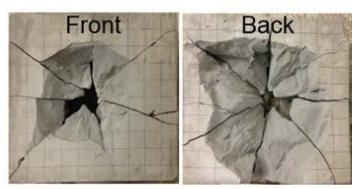

$462 \mathrm{~m} / \mathrm{s}$

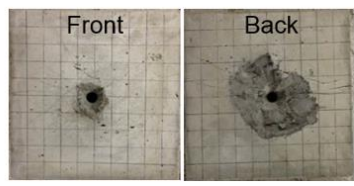

$725 \mathrm{~m} / \mathrm{s}$

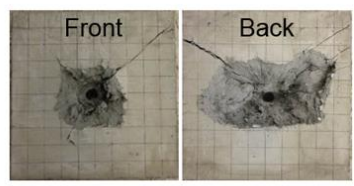

$746 \mathrm{~m} / \mathrm{s}$
Figure 3: Typical local damage for each impact velocity.

\subsection{Penetration diameter and depth}

Figure 4 shows the relationships between the penetration diameter of specimens and the impact velocity of a projectile. The penetration diameter of Plain specimen rapidly increased with an increase of impact velocity. On the other hand, the penetration diameter of SC specimen slightly increased with increasing impact velocity, and those of PVAC specimen was hardly changed by the impact velocity. It can be inferred that the reduction of the damaged diameter was greatly affected by the number of added fibers because the number of fibers was different in each DFRCC specimen even though the volume fraction of the fiber is the same [12]. Since the diameter of PVA fiber was around one-fourth of steel fiber as shown in Table 1, PVA fibers in a specimen are about 16 times as many as steel fibers. Consequently, the large number of added fibers in DFRCC specimens seems to be more efficient to reduce the penetration diameter because the scattered cracking was well controlled by many fibers.

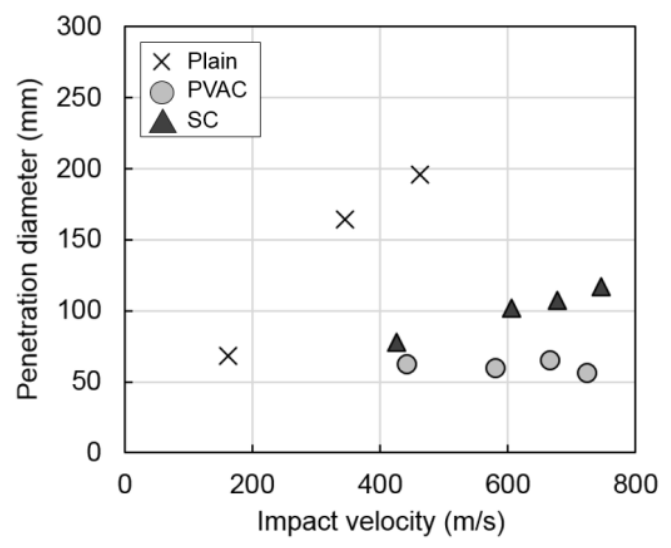

Figure 4: Penetration diameter.

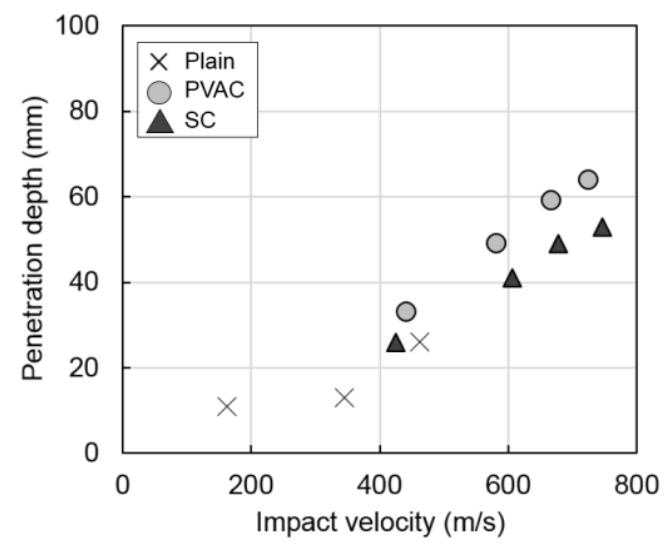

Figure 5: Penetration depth. 
Figure 5 shows the relationships between the penetration depth of specimens and the impact velocity of a projectile. The penetration depth for Plain and DFRCC specimens was affected by the impact velocity. The impact test results indicated that the penetration depth increased with an increase of impact velocity, and that the penetration depth of SC specimen was slightly small as compared with PVAC specimen. In addition, although SC has a low compressive strength compared to Plain, penetration depth of SC specimen was almost same level with that of Plain specimen. For the high performance of SC specimen, the higher stiffness of added fibers was contributed to inhibit the penetration of high velocity projectile. Since the elastic modulus of steel fiber was significantly higher than that of PVA fiber.

\subsection{Scabbing diameter and depth}

Figure 6 shows the scabbing diameter in relation to the impact velocity of projectile. The scabbing of Plain specimens was observed from $345 \mathrm{~m} / \mathrm{s}$ impact velocity, and the diameter increased with increasing impact velocity to reach more than $250 \mathrm{~mm}$, or most of specimen. On the other hand, the first scabbing of DFRCC specimens was appeared over $660 \mathrm{~m} / \mathrm{s}$ impact velocity, indicating that all DFRCC specimens have scabbing capacity of about 2 times for impact velocity more than that of Plain specimens. Furthermore, the number of fibers in DFRCC specimens also deeply influenced the scabbing diameter. The scabbing diameter in perforating of PVAC specimen was smaller than that of SC specimen since the large number of fibers in PVAC specimens could absorb the impact energy and prevent a crack from spreading widely.

The maximum scabbing depth of Plain specimen was $74 \mathrm{~mm}$ under the impact velocity of about $462 \mathrm{~m} / \mathrm{s}$, while those of DFRCC specimens were reduced to the range of 37$48 \mathrm{~mm}$ for the higher impact velocity, as shown in Figure 7. In particular, PVAC and SC specimens have a superior capacity for the limit on the scabbing failure. It is believe that the higher tensile performance of DFRCC contributed inhibition of scabbing.

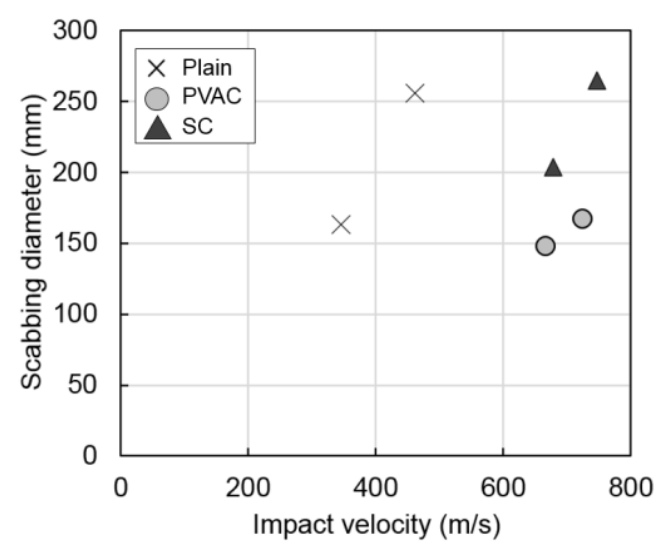

Figure 6: Scabbing diameter.

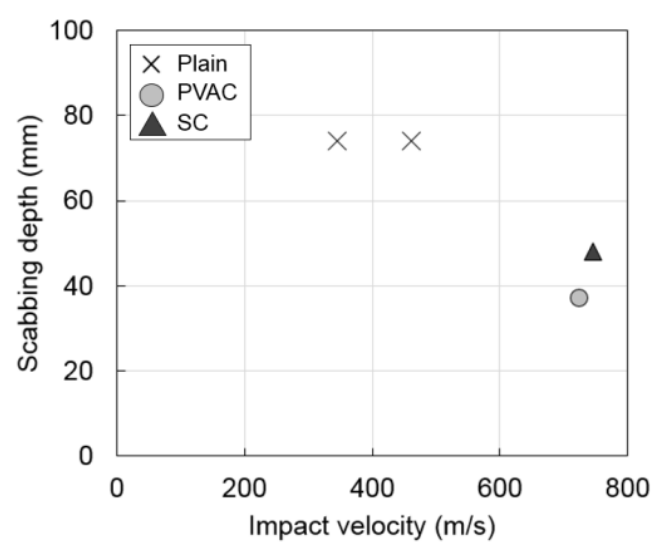

Figure 7: Scabbing depth.

\subsection{Mass loss}

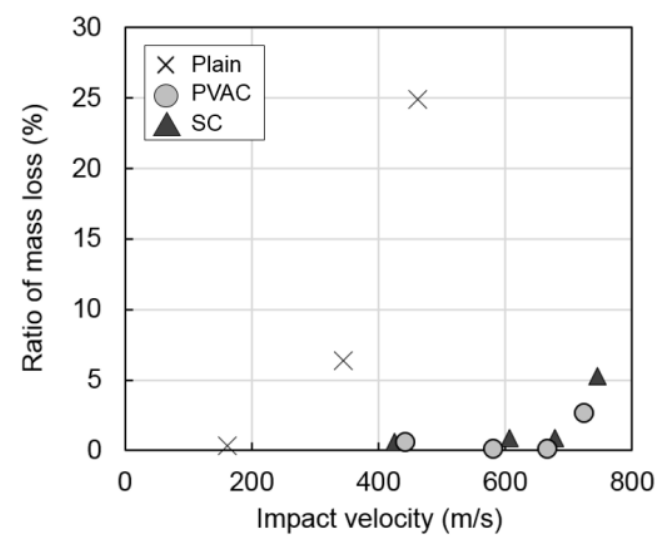

Figure 8: The ratio of mass loss.

Figure 8 shows the relationship between the ratio of mass loss for Plain and DFRCC specimens and the impact velocity. The ratio of mass loss of Plain specimens increased with an increase of the impact velocity while those of DFRCC specimens were considerably reduced even if the impact velocity increased. The ratio 
of mass loss of Plain specimen at the impact velocity of $462 \mathrm{~m} / \mathrm{s}$ was about $25 \%$, on the other hand, those of DFRCC specimens at the impact velocity of near $750 \mathrm{~m} / \mathrm{s}$ were only several percentages. It is important for a protective material to reduce the mass loss due to an impact load, because a dispersed debris may injure people around a blasting building.

\subsection{Analysis of cross-section}

Figure 9 shows the bridging effect of PVA fiber and steel fiber on the capacity for scabbing failure. Although the radial cracks were developed by the impact of the projectile, the growth of the cracks was suppressed by the added fibers.

In addition, Figure 10 presents the boundary between penetration and scabbing in the specimen subjected to perforation failure. The debris of Plain specimen was widely dispersed throughout. However, the debris of DFRCC specimens were slightly scattered around a trajectory of a projectile revealing that DFRCCs have superior impact energy absorbing capacity under high velocity impact of projectile. The superior impact energy absorbing capacity of DFRCCs may be well explained by the penetration path in the cross-section of the specimens. From the figure, the penetration path of the projectile was significantly observed in the cross-section of DFRCC specimens. This behavior is an obvious difference in the failure characteristic between DFRCC and Plain specimens under high-velocity impact. The propagation of wide radial cracks to the back side of the specimens was suppressed by the penetration path, because the critical radial cracks that affect the perforation failure mode were observed at around the ending point of the penetration path in the cross-section of the specimens.

\section{CONCLUSIONS}

The objective of this study is to investigate experimentally the impact resistance of DFRCC specimens under high velocity impact. Based on the experimental results, the main findings of this study, which are useful information for impact resistance control.

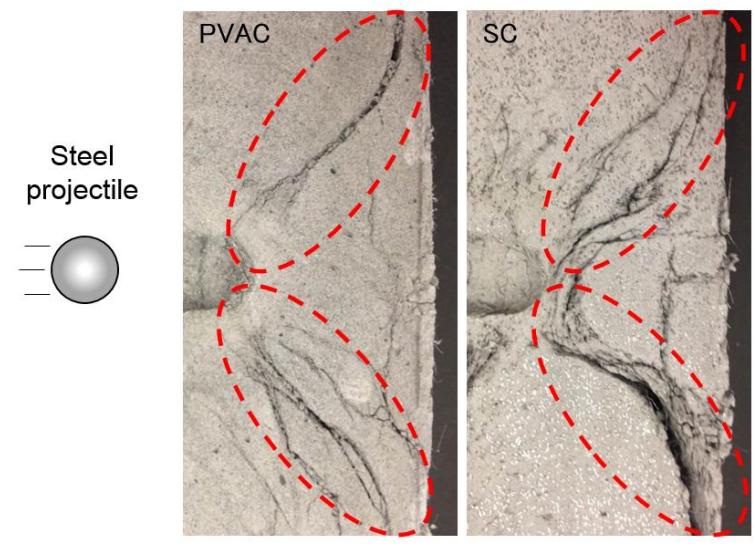

Figure 9: Bridging effect of PVA and steel fibers.

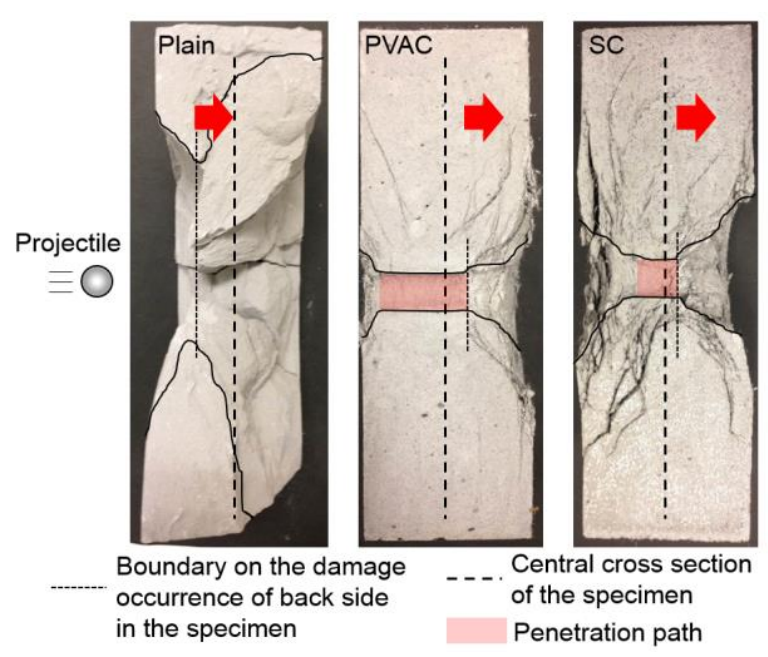

Figure 10: Internal damage patterns.

The scabbing and perforation failures in DFRCC specimens were remarkable inhibited with micro-cracks by added fibers under high velocity impact of projectile, whereas Plain specimens were observed critical failure modes such as scabbing and perforation with broken fragments at the impact velocity of 345 and $462 \mathrm{~m} / \mathrm{s}$, respectively.

Also, the ratio of mass loss of Plain specimens increased with an increase of the impact velocity while those of DFRCC specimens were considerably reduced even if the impact velocity increased.

In addition, the debris of DFRCC specimens were slightly scattered around a trajectory of a projectile. DFRCCs have superior impact energy absorbing capacity under high velocity impact of projectile. In particular, the penetration path of DFRCC specimens was observed after high velocity impact of projectile. 
The penetration path contributed to superior impact energy absorbing capacity of DFRCCs. The propagation of wide radial cracks to back side of DFRCC specimens was suppressed.

\section{ACKNOWLEDGEMENTS}

This work was supported (in part) by the Collaborative Research Project (CRP) of Materials and Structures Laboratory, Tokyo Institute of Technology and Mid-career Researcher Program through NRF (NRF2015R1A2A2A01007705) grant funded by the MEST.

\section{REFERENCES}

[1] Luccioni, B.M., Ambrosini, R.D., and Danesi, R.F. 2004. Analysis of building collapse under blast loads. Eng. Struct. 26:63-71.

[2] Osteraas, J.D. 2006. Murrah building bombing revisited; a qualitative assessment of blast damage and collapse patterns. $J$. Perfor. Constr. Facil. 20:330-335.

[3] Dancygier, A.N., and Yankelevsky, D.Z. 1996. High strength concrete response to hard projectile impact. Int. J. Impact. Eng. 18:583-599.

[4] Beppu, M., Miwa, K., Itoh, M., Katayama, M., and Ohno, T. 2008. Damage evaluation of concrete plates by high-velocity impact. Int. J. Impact. Eng. 35:1419-1426.

[5] Yamaguchi, M., Murakami, K., Takeda, K., and Mitsui, Y. 2011. Blast resistance of polyethylene fiber reinforced concrete to contact detonation. J. Adv. Concr. Tech. 9(1):63-71.

[6] Lee, J.Y., Kim, M.H., Min, K.H., and Yoon, Y.S. 2011. Analysis of behaviors of concrete strengthened with FRP sheets and steel fibers under low-velocity impact loading. Journal of the Korea Institute for Structural Maintenance and Inspection 15(4):155-164. (In Korean).

[7] Yang, E.H., and Li, V.T. 2012. Tailoring engineered cementitious composites for impact resistance. Cem. Concr. Res. 42: 1066-1071.

[8] Maalej, M., Quek, S.T., and Zhang, J. 2005. Behavior of hybrid-fiber engineered cementitious composites subjected to dynamic tensile loading and projectile impact. J. Mater. Civ. Eng. 17:143-152.

[9] Farnam, Y., Mohammadi, S., and Shekarchi, M. 2010. Experimental and numerical investigations of low velocity impact behavior of high-performance fiberreinforced cement based composite. Int. J. Impact. Eng. 37:220-229.

[10] Yang, E.H., Yang, Y., and Li, V.T. 2007. Use of high volumes of fly ash to improve ECC mechanical properties and material greenness. ACI Mater. J. 104(6):620-628.

[11] Atou, T., Sano, Y., Katayama, M., and Hayashi, S. 2013. Damage evaluation of reinforced concrete columns by hyper velocity impact. Procedia Eng. 58:348354.

[12] Kim, H., Kim, G., Gucunski, N., Nam, J., and Jeon, J. 2015. Assessment of flexural toughness and impact resistance of bundletype polyamide fiber-reinforced concrete. Compos. Part B: Eng. 78:431-446. 